\title{
The regulation of ovary and conceptus on the uterine natural killer cells during early pregnancy
}

\author{
Han Gong ${ }^{1,2 \dagger}$, Yilu Chen ${ }^{1 \dagger}$, Jingjie X $u^{1}$, Xingxing Xie ${ }^{1}$, Dainan Yu${ }^{1}$, Bei Yang ${ }^{1}$ and Haibin Kuang ${ }^{1,3^{*}}$ (D
}

\begin{abstract}
Uterine natural killer (UNK) cells are short-lived, terminally differentiated and the most abundant lymphocytes in the uterus which play a crucial role in the spiral arteriole modification and establishment of successful pregnancy. Dysregulation of uNK cells has been linked to gestational implications such as recurrent pregnancy loss, preeclampsia and fetal growth retardation. There is evidence showing that progesterone and estrogen can regulate the recruitment, proliferation, differentiation and function of UNK cells via direct action on intracellular nuclear receptors or through intermediary cells in the uterus during early pregnancy. As the deepening of related research in this field, the role of conceptus in such regulation has received extensive attention, it utilizes endocrine signaling (hCG), juxtacrine signaling (HLA-C, HLA-E, HLA-G) and paracrine signaling (cytokines) to facilitate the activities of UNK cells. In addition, under the influence of ovarian hormones, conceptus can increase expression of PIBF and HLA-G molecules to reduce cytotoxicity of uNK cells and promote angiogenesis. In this review, we aim to concentrate on the novel findings of ovarian hormones in the regulation of UNK cells, emphasize the regulatory role of conceptus on uNK cells and highlight the proposed issues for future research in the field.
\end{abstract}

Keywords: Uterine natural killer, Ovary, Conceptus, Regulation, Pregnancy

\section{Background}

Uterine natural killer (uNK) cells are short-lived, terminally differentiated and the most abundant granulated lymphocytes present in the non-pregnant endometrium and pregnant decidua of human uteri $[1,2]$. In non-pregnant endometrium, the proportion of uNK cells in the endometrial stromal cells increases since the proliferative phase $(10 \%)$ of menstrual cycle and reaches the maximal level in the late secretory phase (20\%). After pregnancy, the proportion sustains to increase due to a large influx of NK lymphocytes from peripheral circulation (30\%) [2] and the cells differentiate to present abundant cytoplasmic and membranebound granules and enlarge to $50 \mathrm{~mm}$ in diameter.

\footnotetext{
*Correspondence: kuanghaibin@ncu.edu.cn

${ }^{\dagger}$ Equal contributors

'Department of Physiology and Jiangxi Provincial Key Laboratory of Reproductive Physiology and Pathology, Basic Medical College, Nanchang University, Nanchang, Jiangxi 330006, People's Republic of China

${ }^{3}$ Department of Physiology, Basic Medical College, Nanchang University,

Nanchang, Jiangxi 330006, People's Republic of China

Full list of author information is available at the end of the article
}

Uterine NK cells are transient and begin to apoptosis to a much less prominent population of lymphocytes after early pregnancy [3]. Immunophenotyping experiments in both rodents and humans indicate that these pregnancy-associated transient lymphocytes resemble the CD56bright circulatory NK cell (cNK) subsets [4]. These cells are phenotypically identical to the typical NK cells, which are characterized as presence of $\mathrm{CD}^{+} 6^{+}$and $\mathrm{CD}^{-}$. In addition, they also lack of $\mathrm{CD16}$, an important mediator of antibody-dependent cellular cytotoxicity (ADCC) for NK cells to lyse target cells and are less cytotoxic than other subsets of cNK cells. The ability to produce large amounts of cytokines upon activation is another important characteristic for these cells [5]. Especially for uNK cells, which are shown to play an important role in early pregnancy, secreting cytokines is the main strategy to regulate trophoblast invasion, spiral arterial modification, placental formation and finally establish successful pregnancy [6]. 
Uterine NK cells also have additional characteristics that are unique to themselves [1, 7]. A recent microarray analysis has provided a detailed comparison of gene expression between uterine NK cells and their corresponding CD56bright NK population present in circulatory blood vessels [8]. The significant differences include selective overexpression of lectinlike receptors (NKG2C, NKG2E), KIRs and other potential immunoregulatory proteins (Galetin-1 and Glycodelin) in uNK cells but not in cNK cells. One possible explanation for the observed differences refers to uNK cells represent a distinct lineage of NK cells from hematopoietic precursors. Otherwise, the distinctions are probably a direct reflection of CD56bright NK cells differentiation in the uterine microenvironment. Previous reviews have summarized the role of estrogen and progesterone in the regulation of uNK cell recruitment, proliferation, differentiation and function via direct action on intracellular nuclear receptors or through intermediary cells in the uterus during early pregnancy $[9,10]$. In this review, we emphasize the regulatory role of conceptus that have not been described before and are critically dedicated to construct a thorough regulatory network of uNK cells during early pregnancy.

\section{Regulation of ovary on the uNK cells}

The anterior pituitary gland starts to synthesis follicle stimulating hormone (FSH) and luteinizing hormone (LH) since puberty and stimulate ovarian cells to synthesis progesterone and estrogen in a cyclic manner. After ovulation, the levels of progesterone and estrogen reach a peak to create a "window of implantation" 6-10 days and do not fall until the end of 10th week of gestation in human. After that, conceptus-derived placenta replaces ovarian cells to secret progesterone and estrogen.

\section{Regulation of estrogen and progesterone on the proliferation and recruitment of uNK cells}

The changes that occur in uNK cell number in early pregnancy are attributed to self-renewal or trafficking of cNK cells [6]. Regulatory evidence of estrogen in uNK self-renewal is not entirely clear. Administration of estrogen in the culture medium did not significantly affect the proliferation of $\mathrm{uNK}$ cell in vitro [11] However, in tamoxifen (anti-estrogen)-exposed mouse, proliferative activities of uNK cell were observed to be interfered in vivo [12], which may be account of permissive role of progesterone in vivo or other factors. However, mechanism of progesterone-mediated selfrenewal is much clear. Some studies have showed that progesterone can stimulate endometrial stromal cells secreting IL-15 to promote self-renewal of uNK cells [13].

Both estrogen and progesterone play an indispensable role in uNK cell recruitment. Progesterone was initially found to upregulate VEGF and VEGF receptors on the endometrial stromal cells in an in vitro model of decidualization. VEGFs are factors required in angiogenesis, so they can improve histological perfusion to assist uNK cells homing [14]. Subsequent experiment has showed that both estrogen and progesterone can also increase homing through the increased expression of L-selectin and $\alpha$-integrin on the surface of circulatory CD56bright NK cells [15] and CXCL10/CXCL11 on endometrial cells [16]. Recently, a study carried out by our lab has provided more visualized evidence to their recruited action. Uterine NK cells did not appear in mice uterus on day 2 of pregnancy, a time with low or no estrogen and progesterone. However, they began to distribute in uterine blood vessels in next day 3 and 4 of pregnancy and the distributing pattern of them is identical to the ovariectomized mice after administration of estrogen and progesterone, which further confirmed their role in homing of uNK cells during early pregnancy [17].

\section{Regulation of estrogen and progesterone on the function of uNK cells}

Estrogen and progesterone can regulate the function of uNK cells through a direct or an indirect way. In direct way, estrogen and progesterone couple to their nuclear receptors to activate gene expression of immunomodulatory or angiogenic proteins in the uNK cells. In mice model, they have been shown to upregulate the expression of galectin-1, an immunosuppressant, in decidual NK population [9]. However, there is a slight difference in their regulatory effect on angiogenesis of uNK cells. Estrogen increases secretion of CCL2 in UNK cells to construct blood vessels in endometrium [18], while progesterone induces the expression of IFN- $\gamma$ [19]. In indirect way, endometrial stromal cells, trophoblast cell, $\mathrm{T}$ lymphocyte are proposed intermediary cells transducing effects of progesterone. In response to progesterone, the cells produce Hoxa-10 [20], progesterone-induced blocking factor [21], and Th2 cytokines [22] respectively to reduce cytotoxicity of $\mathrm{uNK}$ cells. In general, both direct and indirect ways are necessary for maintenance of pregnancy.

\section{Potential mechanisms of steroid hormones action on the uNK cell}

Biological activities of steroid hormones are predominantly mediated by binding to respective nuclear receptor to initiate gene transcription, which is considered as the most classical mechanism of steroid hormones. In 1996, Henderson et al. confirmed mRNA expression of ER $\beta 1$, $\mathrm{ER} \beta \mathrm{cx} / \beta 2$ and glucocorticoid receptor (GR) in purified uNK cells, but failed to find ER $\alpha$ or progesterone receptor (PR), and further colocalized immunohistochemistry technique performed on uNK cells only confirmed 
presence of protein ER $\beta 1$ and GR [23]. However, when $E R \alpha$ and ER $\beta$ knock-out bone marrows were transplanted in RAG-2-/ $-/ \gamma \mathrm{c}-/-$ mice, a mutant lack of all lymphocyte lineages, uNK cells were presented in a cyclical distribution as usual and did not show significant changes on the angiogenesis. It seems that ERs do not play a role in regulation of uNK cells [24]. A recent study discovered a new orphan receptor- estrogen receptor related beta (ERR $\beta$, ESRRB/NR3B2) located in the nuclei of uNK cells. The receptor shares significant sequence homology with ER $\alpha$ and $\beta$ and might transduce the effects of estrogen [25]. This provides an alternative evidence that classical mechanism is still applicable in uNK cells, yet not through conventional ERs. While we continue to identify novel subpopulation of ERs in the nuclei of uNK cells, conventional ERs, ER $\alpha$ and ER $\beta$ have been trafficked into cell surface to initiate intracellular signaling pathway in mice hypothalamus and striatal neurons. Especially ERßs were found to couple to metabotropic glutamate receptor 2 (mGluR2) on cell membrane and activate its intracellular signaling to inhibit phosphorylation of transcription factor cAMPresponse element binding protein (CREB) in the cells (Fig. 1) [26]. However, the presence of non-classical pathways in uNK cells is unknown.
As described above, PRs have not been identified in uNK cells. Effects of progesterone are postulated to perform by other common nuclear receptor-glucocorticoid receptors (GR), because progesterone was illustrated to share structural similarity with glucocorticoid [23]. Progesterone was proved to inhibit CD69 and IFN- $\gamma$ expression of human uNK cells and this effect cannot be reversed by CDB-2914, an antibody specific to progesterone. However, RU486 (antagonist of progesterone and glucocorticoid) could restore expression of CD69 and IFN- $\gamma$ on uNK cells, which indirectly proved GR may be the target of progesterone [19]. Except for classical nuclear receptor, non-classical pathways of progesterone may also play an indispensable role in such regulation. In fact, the non-classical pathway of progesterone has been studied by many investigators over the past 20 years. Membrane receptor component 1 (PGMRC1) and progesterone membrane receptors (mPRs), two membrane proteins unrelated to classical PRs (Fig. 1), have been proven to be employed in the brain and reproductive tissues in mammals [26-28]. In human sperm and female reproductive tissue, they function as G protein- coupled receptors (GPCRs) to activate downstream activated or inhibitory G-proteins [29]. What's more, in human NK cells, depolarization induced by

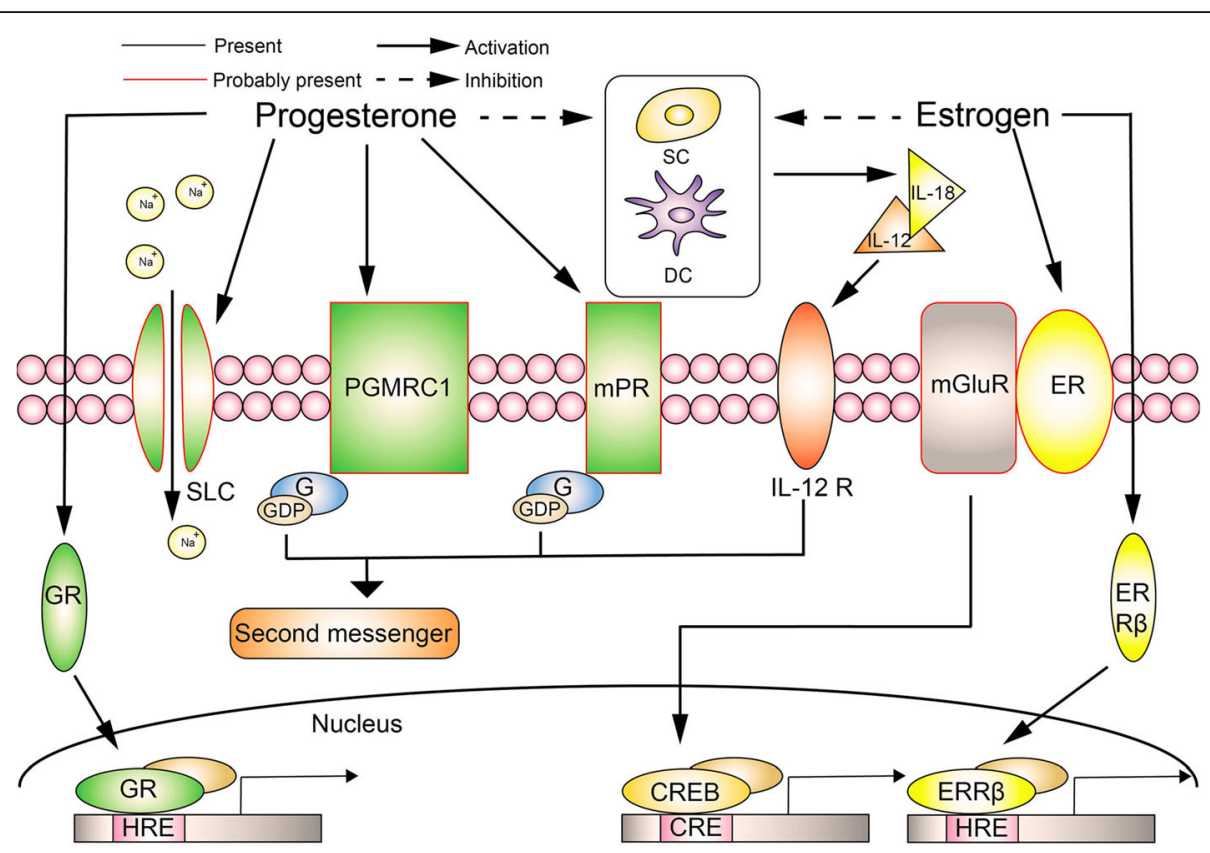

Fig. 1 Potential mechanisms of steroid hormones action on the uNK cells. Through classical steroid receptors (e.g. GR, ERRß), non-classical pathways or intermediary cells in the surrounding, progesterone and estrogen probably affect gene transcription, secondary messenger and membrane potential to regulate the activities of uNK cells. Among them, non-classical pathways referring to ion channels (e.g. SLC) and membrane-bound receptors are mainly contributed to rapid actions of the hormones. For progesterone, PGMRC1 and mPR are two potential candidates of membrane-bound receptors on the uNK cells and function as $G$ protein-coupled receptors to activate or inhibit downstream $G$ protein. For estrogen, its membrane-bound receptors may be coupled to mGluR2 and initiate intracellular signaling pathway of mGluR2 to regulate UNK cells activities. Otherwise, both progesterone and estrogen are likely to reduce IL-18 level in endometrial stromal cell (SC) and dendritical cells (DC) to inhibit cytotoxicity of uNK cells and improve pregnant outcomes 
steroid-like $\mathrm{Na}^{+}$channel (SLC) was identified due to progesterone [30]. Whether uNK cells employ the same mechanism as the cells, additional researches are still required.

In addition to direct effects of sexual hormones on the uNK cells, hormones could also regulate uNK cells indirectly, via action on neighboring cells that serve as intermediaries. In vitro studies indicate that estradiol and progesterone can reduce IL-18 level in the cultured endometrial stromal cells from patients who experienced spontaneous abortion, which helps to improve the pregnant outcomes [31].This is because IL-18 is a strong enhancer of IL- 12 that can behave as proinflammatory cytokine engaging in cytolytic effects of uNK cells at excessive doses to cause pregnancy loss (Fig. 1) [32]. Otherwise, IL-18 synthesis were also found in monocyte-derived dendritic cells (mDCs) instead of stromal cells, thus, $\mathrm{mDCs}$ are also regarded as a potential intermediators of sex steroid hormones on uNK cells [33].

Collectively, there is some evidence related to potential mechanisms involved in the regulation of progesterone and estrogen on uNK cells. It may act through classical steroid receptors in the nuclei, non-classical pathways or through intermediary cells in the surrounding of uNK cells. Among them, non-classical pathways referred to intracellular kinase signalings or and membrane-bound receptors are mainly responsible for rapid effects of the hormones, which can be considered as a possible mechanism of dramatic tissue remodeling occurring in the early pregnancy. Thus, non-classical regulation of estrogen and progesterone on uNK cells is a proposed subject for future research.

\section{Regulation of conceptus on the uterine NK cells}

Except for ovaries, conceptus also plays a vital role in the regulation of uNK cells. However, the regulations were less discussed in previous review literatures. In fact, conceptus can signal to uNK cells in more various ways than ovaries, which mainly rely on endocrine signaling (e.g. estrogen, progesterone). Conceptus nearly utilizes all possible signaling ways to deliver signals to uNK cells. These signals include: (1) Human chorionic gonadotropin (hCG), endocrine molecules act on the whole body via entering blood stream; (2) cytokines and chemokines, paracrine signals act locally via simple diffusion; (3) HLAs, contact-dependent signals act directly by binding cell surface receptors on target cells.

\section{Hormonal regulation: hCG}

HCG is a glycoprotein hormone exclusively secreted by trophoblast cells during pregnancy [34]. It can be detected in the blood on 10 days after fertilization and peaks at 10th and 11th week of pregnancy, and then later declines since 12th week [35]. This temporal distribution of hCGs implicates its roles in early pregnancy and coincides with the life cycle of uNK cells. Therefore, hCG can be considered as a potential regulator of uNK cells. Although hCG has been ever added into endometrial leukocyte-rich fractions in culture medium, it made no significant changes on numbers of CD56bright (uNK) cells in the experiment [6]. However, the role of hCG in regulation of uNK cell proliferation was re-examined in a recent study. The research observed that mature hCG molecules with $\mathrm{N}$-linked carbohydrate side chains could promote $\mathrm{UNK}$ cell proliferation. But the impact is not achieved through classical hCG/LH receptors for hCGs, it acts via mannose receptors (CD206). Only hCG molecules with carbohydrate chains can bind to the carbohydrate receptors and exert their actions on uNK cells [36]. The divergence in the above experiments may be attributed to the different types of hCG molecule used. The hCG molecules added in the previous experiment was believed to be de-glycosylated and cannot be recognized by the mannose receptors (CD206) on uNK cells. Another probable cause of failure in previous experiment is the culture medium contained too excess D-mannose, which was originally used to support cell growth. D-mannose molecules serve as competitive antagonists binding to the active sites of CD206 receptors and impair access of glycosylated hCG molecules to the receptor binding sites, resulting in an unsuccessful activation of uNK proliferation. Evidence above shed new insight into cross-talk between hCGs and uNK cells. Still, additional interactions are remained to be established.

\section{A complicated network of regulation: Cytokine}

Prior work has illustrated the regulation of endometriumderived cytokines on conceptus [37-39]. As several cytokines (IL-1, IL-6, IL-10, TNF- $\alpha$, TNF- $\beta$ ) secreted by conceptus have been found in the maternal-fetal interface [37], studies related to reversed regulation of conceptus on the endometrium are onset. uNK cells, as the predominant population of lymphocytes in the endometrium, are the primary targets for conceptus-derived cytokines and relevant evidence of regulation has been ascertained progressively using clinical samples and rodent models.

Prolactin-like protein A (PLP-A) and prolactin family 8 subfamily a member 2 (PRL8A2) are two well-studied members of prolactin family in this field. They are a subset of conceptus-derived cytokines with unique functional characteristics. They neither utilize classical receptors for prolactin nor increase production of IFN- $\gamma$ in uNK cells $[40,41]$. In fact, the ability of uNK cell to secret IFN- $\gamma$ is downregulated by the two prolactin-like proteins. How the proteins achieve their biological activities, mechanisms 
involved are still unclear, only intracellular $\mathrm{Ca} 2+$ mobilization was detected upon activation of these molecules [40, 42]. It is noteworthy that, through respective receptors, the prolactin-like proteins and prolactin can contribute to regulation of uNK cell simultaneously without disturbance to each other. In this way, PLP-A and PRL8A2 can modulate effects of prolactin to avoid inappropriate release of IFN- $\gamma$ in uNK cells.

Chemokines constitute a group of cytokines that control communication and migration of immune cells. According to location of their cysteine residues, chemokines are classified into four groups: CXC, CC, CX3C and XC [43]. CXC chemokines are the first family to describe, which are involved in the regulation of conceptus on uNK cells. Through comparing chemokine receptor repertoires of cNK and uNK cells, preferential expression of CXCR3 and CXCR4 has been found on CD16- uNK cells. Then CXCL12, a ligand to CXCR4, was demonstrated to be broadly expressed in invasive trophoblast cells in vivo [44]. In vitro experiment was also performed, culture of trophoblast cells showed concentration of CXCL12 can be up to $384.6 \pm 90.7 \mathrm{pg} / \mathrm{ml}$ after $60 \mathrm{~h}$ incubation, whereas ligands for CXCR3 were all below minimal detectable concentration after $48 \mathrm{~h}$ incubation $[44,45]$. Based on data above, we would predict that, for conceptus, CXCL12/CXCR4 axis is the main signaling of CXC family to induce recruitment of uNK cells. CXCR7 is another receptor for CXCL12 and has $\sim 10$ folds higher affinity to CXCL12 in comparison to CXCR4 [46]. Researchers postulated CXCL7 might have an overriding advantage in mediating CXCL12 signaling. However, both immunohistochemistry and flow cytometry failed to identify CXCR7 molecules on peripheral NK cells of mice and human [47]. Thus, CXCR7 seemed not to be another desirable candidate receptor of CXC family in such recruitment. Interestingly, CXCL12/CXCR4 axis was also found to participate in $\mathrm{cNK}$ differentiation in the uterus through JNK1/2/MAPK and ERK/MAPK signaling pathways [48]. CXCL-12 molecules stimulated uNK cells to generate diverse factors to support conceptus invasion, which further complicated functions of CXCL12-mediating signaling pathways.

Both human and rodent studies have also suggested a potent role of monocyte inflammatory protein (MIP)- $1 \alpha$ and macrophage chemotactic protein (MCP)-1 in migration of peripheral NK cells [49-51], which belong to CC chemokine family. Peripheral NK cells of human and mice constitutively express CCR2 for MCP-1, as well as CCR5 for MIP- $1 \alpha$ in response to their chemotactic regulation [52]. Because MIP- $1 \alpha$ and MCP-1 are also present in uterus during estrous cycle and increase in the early pregnancy, they are likely to be involved in the recruitment of uNK cells. In human model, Penelope M. Drake et al. confirmed localization of MIP-1 $\alpha$ mRNA and protein in cytotrophoblast cells. At the same time, subsequent addition of anti-MIP- $1 \alpha$ antibodies eliminated chemotaxis of $66.8 \pm 20.0 \%$ CD56bright NK cells in cytotrophoblast conditioned medium, which implied that MIP- $1 \alpha$ is responsible for conceptus-mediated chemotaxis of CD56bright NK cells in human [53]. As for MCP-1, although its level is in parallel to number of uNK cells in human endometrium, its expression in conceptus has not been proved. In mouse model, Chantakru et al. suggested recruitment of NK cells in the uterus of pregnant mice is independent of chemotaxis of MIP- $1 \alpha$ and MCP-1, whether diameter or distribution of uNK cells was all identical in CCR2, CCR5 and MIP-1 $\alpha$ knock-out mutants and controls [52]. So far, no other researches have illustrated the exact role of MIP-1 $1 \alpha /$ CCR2 or MCP-1/CCR5 axis of uNK cells in mice models. Thus, chemotactic ability of conceptusderived CC chemokines on uNK cells may be only conserved in human rather than rodents.

\section{Juxtacrine regulation: a novel but vital signaling specific to conceptus}

One of significant actions of NK cells in the peripheral blood is to attack infected cells without prior sensitization. They can distinguish infected cells from normal cells by recognizing alternation in MHC class I molecules on cell surface [54]. In human, the MHC class I molecules that play an important role in NK cell recognition are members of $\mathrm{MHC}$ class Ia (HLA-C) and Ib (HLA-E, HLA-F, HLA-G, MIC) [55]. Among them, only HLA-C, HLA-E and HLA-G are particularly expressed by fetal- derived trophoblast cells, the only cells that directly contact to NK cells in the uterus $[56,57]$. Thus, the molecules can serve as ligands to activated or inhibitory receptors on uNK cells to regulate their activities in a contact-dependent manner. HLA-E and HLA-G molecules constitute a more complicated network of regulation on uNK cells, which will be discussed in Chapter III. Here we focus on the interaction between HLA-C molecules and uNK cells.

According to a dimorphism at position 80 of the $\alpha 1$ domain, HLA-C molecules on trophoblast cells are classified into 2 classes (Fig. 2): $\mathrm{C} 1$ and $\mathrm{C} 2$ allotype. $\mathrm{C} 1$ allotype are mainly bound by inhibitory KIR2DL2 and KIR2DL3 on the uNK cells, whereas C2 allotype are preferentially bound by inhibitory KIR2DL1 and activated KIR2DS1 [58]. Killer immunoglobulin-like receptors (KIRs) are molecules developed by NK cells in recognition of HLA-C molecules on cell surface and divided into activated and inhibitory receptors based on their action on NK cells [59]. Dependent on presence of activated receptors, over 350 KIR genotypes are basically divided into 2 haplotypes: A (only inhibitory receptors) and $B$ (inhibitory and activated receptors), which can be 


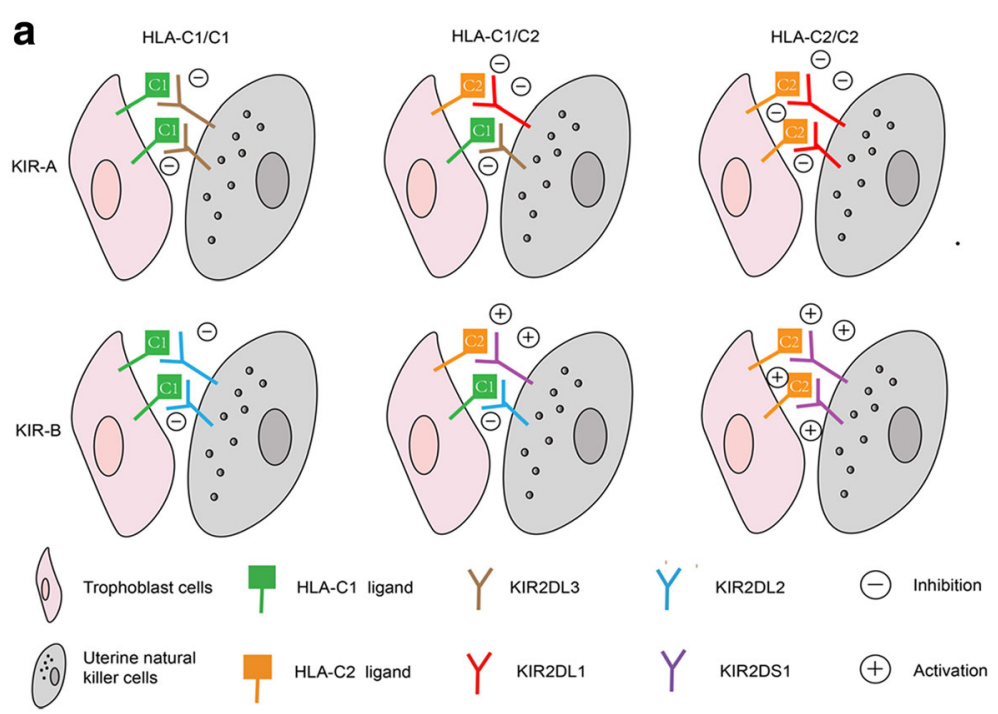

b

\begin{tabular}{|l|l|l|l|}
\hline Receptor & HLA ligand & Function & KIR Region \\
\hline$Y$ KIR2DL3 & HLA-C1 ligand & $\Theta$ slight inhibition & Cen-A \\
\hline$Y$ KIR2DL1 & HLA-C2 ligand & $\Theta_{\odot}$ intensive inhibition & Cen-A \\
\hline$Y$ KIR2DL2 & HLA-C1 ligand & $\Theta$ slight inhibition & Cen-B \\
\hline$Y$ KIR2DS1 & HLA-C2 ligand & $\oplus_{\oplus}$ intensive activation & Tel-B \\
\hline
\end{tabular}

Fig. 2 KIR-A/homologous C2 and KIR-B/homologous C1 are two high-risk combination. a All possible combination of maternal KIR haplotypes with trophoblastic HLA-C ligands. Combinations with intensive inhibition are failure to activate UNK cells to secrete relevant angiogenic cytokines and more vulnerable to undergo pregnancy losses. Thus, KIR-A/homologous $\mathrm{C} 2$ and KIR-B/homologous $\mathrm{C} 1$ are two high-risk combinations than other combinations. b Binding properties of the main KIRs for fetal HLA-C

subdivided into centromeric and telomeric regions (Cen-A, Tel-A, Cen-B, Tel-B) [60, 61]. The great diversity of maternal KIRs and fetal HLA-C ligands means that a huge number of combinations will be generated in pregnancies and combinations failed in activation of uNK cells are attributed to pathogenesis of preeclampsia, fetal growth restriction and recurrent pregnancy, which can be explained by poor angiogenesis [62]. Some studies have demonstrated frequencies of affected pregnancies increased in KIR AA mother, especially accompanied with homologous $\mathrm{C} 2$ fetus [63]. Recently, another high-risk combination is identified by direct embryo HLA-C genotyping, which is the haplotype B/ homologous $\mathrm{C} 1$. In overall, the two combinations can cause a $51 \%$ increased risk of pregnancy loss over all other combinations. What's more, the interaction of HLA-C and KIRs not only can determine the possibility of pregnancy losses but also the timing of them. Because the homologous $\mathrm{C} 1$ embryos were observed to undergo more biochemical pregnancy losses than clinical losses, which caused its latent discovery in clinic practice compared to the haplotype $\mathrm{A} /$ homologous $\mathrm{C} 2$ combination [64].
Combined action of ovary and conceptus on uNK cells

Evidence above has shown that whether ovary or conceptus plays a vital role in the regulation of uNK cell activities, however, it is also important to note that they can act in synergistical manners. Animal and human studies have suggested that progesterone regulates expression of progesterone induced blocking factor (PIBF) and HLA-G in trophoblast cells to modify uNK cells function. Initially, PIBF proteins were found to be synthesized by $\gamma \delta \mathrm{T}$ lymphocytes in response to progesterone in circulatory system. The proteins exert their immunosuppressive effects on peripheral NK cells and maintain normal pregnancy [65]. Then PIBF proteins attract considerable attention as a novel part of nonclassic regulatory pathway of progesterone. In fact, $\gamma \delta \mathrm{T}$ lymphocytes are not the only cellular resource of them. A human study illustrated that trophoblast cells in the placenta could express PIBF proteins of 30,50 and $90 \mathrm{kDa}$ in first trimester [66]. Because neither PRs nor homologies were verified in uNK cells [23], such nonclassical regulation was required by uNK cells in response to progesterone. Moreover, as an immunosuppressant, PIBF proteins are likely candidates in 
mediating immune tolerance of uNK cells to conceptus. The postulation has not been confirmed until Bogdan et al. demonstrated PIBF proteins co-localized with perforins in $\mathrm{DBA}^{+}$uNK cells [21]. In the study, progesterone was administrated to these cells and reduced $47 \%$ perforin ${ }^{+}$cells from them, which directly proved the presence of the non-classical pathway of progesterone in the regulation of uNK cells.

In studies of HLA-G molecules, progesterone is also shown to be correlated with expression of HLA-G molecules on cell surfaces. Progesterone upregulates HLA-G molecules via a novel progesterone response element (PRE), which is located on promoter of HLA-G genes in JEG-3 cell models and shares to $60 \%$ similarity to mouse mammary tumor virus PRE [67]. Within the element, it can enhance HLA-G expression on JEG-3 carcinoma cells and human cytotrophoblast cells in vitro [68]. What's more, normal human endothelial cells of heart vessel and smooth muscle cells do not present HLA-G molecules on their surface or in the cytoplasm, but they are able to present the molecules after progesterone treatment [69]. Thus, HLA-G is likely to be another intermediary molecule involved in progesterone-mediated indirect modulation of uNK cells.

Unlike classical MHC class Ia molecules, HLA-G molecules are exclusively expressed by fetus-derived cells like extravillous cytotrophoblast cells or chorionic endothelial cells in the maternal-fetal interface [9, 70]. In addition, their presence in endometrial stroma cells, which are maternal-derived, has also been proved [71]. However, not all HLA-G molecules are expressed on cell surface. Some alternative splice transcripts of HLA-G mRNA lack exons encoding transmembrane or cytoplasmic translated domains and are translated as soluble forms [72]. For NK cells, they only have 2 types of receptors for HLA-G molecules: one is ILT2 for membrane-bound isoforms; the other is KIR2DL4 for soluble isoforms [73, 74]. Despite of different isoforms, engagement of HLA-G molecules yields completely the same consequence that HLA-G molecules inhibit cytotoxicity of uNK cells and increase the secretion of IL-6, IL-8, and TNF- $\alpha$, which play roles in spiral artery modification [75]. HLA-G molecules also can reduce cytotoxicity of uNK cells without the help of their cell surface receptors. A leader peptide derived from HLA-G molecules can bind to HLA-E molecules on cell surface and stabilize their expression. The corresponding receptor of HLA-E that is highly expressed on uNK cells is NKG-2A. NKG-2A is an inhibitory receptor and present on uNK cells in a complex with CD94 [76]. Thus, HLA-G molecules can indirectly activate inhibitory NKG-2A/CD94 to reduce uNK cell cytotoxicity by promoting HLA-E molecules expression.

\section{Conclusion}

In general, ovary and conceptus can regulate activity of uNK cells in a separated or combined manner (Fig. 3). Dysregulation of uNK cells has been linked to gestational implications such as recurrent pregnancy loss, preeclampsia and fatal growth retardation. Given poor understanding of the mechanisms involved in the

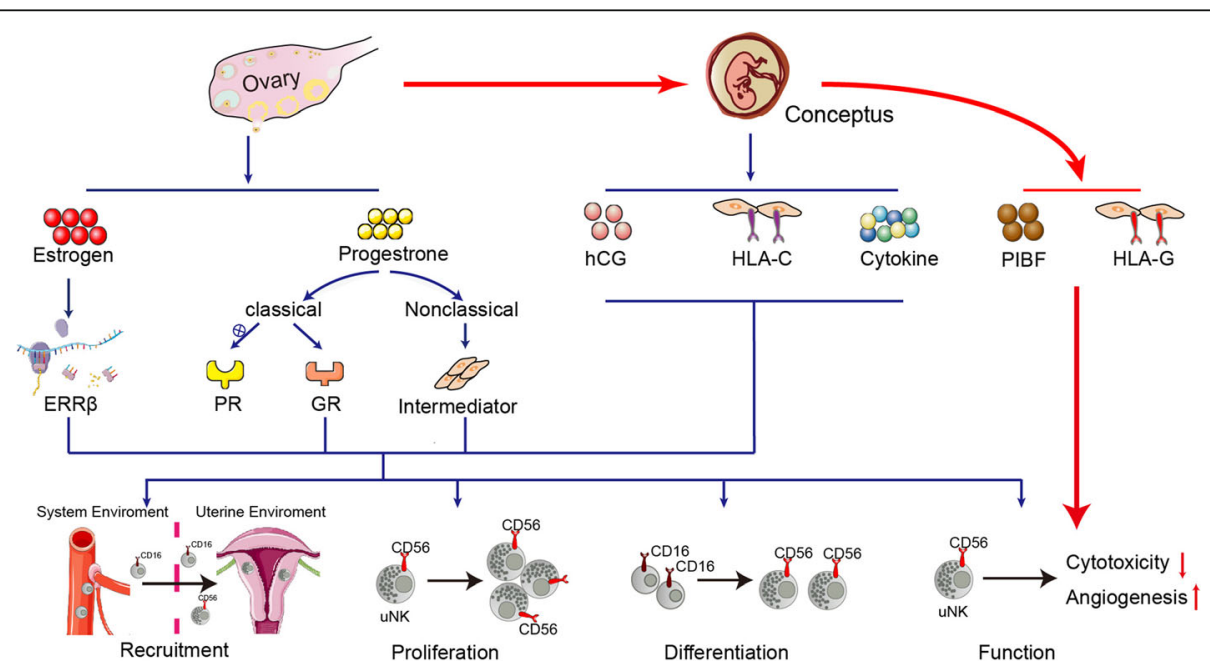

Fig. 3 The regulation of ovary and conceptus on the uNK cells. In early pregnancy, endocrine signaling (e.g. estrogen and progesterone) of ovarian cells can regulate recruitment, proliferation, differentiation and function of uNK cells via direct action on intracellular nuclear receptors (e.g.ERRß, GR) or through intermediary cells in the surroundings (e.g. T lymphocytes and endometrial stromal cells). Compared to ovaries, besides endocrine signaling (e.g. hCG), conceptus also utilizes juxtacrine signaling (e.g. HLA-C) and paracrine signaling (e.g. cytokines) to facilitate activities above of uNK cells. In addition, under the influence of ovarian hormones, conceptus can increase expression of PIBF and HLA-G molecules to reduce cytotoxicity of uNK cells and promote angiogenesis 
pathogenesis of the diseases, current therapies are all specialized for the hormonal dysregulation of uNK cells. Through giving a more comprehensive overview of regulatory network of them in the uterine microenvironment, our work can hopefully provide more conceptusderived targets for the development of novel and effective therapies.

\section{Abbreviations}

cNK: Circulatory natural killer; CREB: CAMP- response element binding protein; ERRß: Estrogen receptor related beta; FSH: Follicular stimulating hormone; GPCR: G-protein coupled receptor; GR: Glucocorticoid receptor; HCG: Human chorionic gonadotropin; HLA: Human leucocyte antigen; KIR: Killer immunoglobulin-like receptor; LH: Luteinizing hormone; MCP: Macrophage chemotactic protein; mDCs: Monocyte-derived dendritic cells; mGluR2: Metabotropic glutamate receptor 2; MHC: Major histocompability complex; MIP: Monocyte inflammatory protein; MPR: Progesterone membrane receptor; PGMRC1: Progesterone membrane receptor component 1; PIBF: Progesterone induced blocking factor; PLPA: Prolactin-like protein A; PRE: Progesterone response element; PRL8A2: Prolactin family 8 subfamily a member 2; SLC: Steroid-like $\mathrm{Na}+$ channel; uNK: Uterine natural killer

\section{Acknowledgments}

The present study work was supported by the National Natural Science Foundation of China (grant nos. 81671486, 31260248, 81270668 and 81460226) and 555 Project of Jiangxi Province Gan Po Excellence and Academic and Technical Leader Foundation of Jiangxi province.

\section{Availability of data and materials}

All data supporting the conclusion of this article are included in this published article.

\section{Authors' contributions}

$H G, Y L C$ and HBK have been contributed to the initial literature search, acquisition, analysis and design the first draft of article. XXX, DNY and BY has been included in review the manuscript and further edition. JJX is mainly responsible for designing illustrated graph and HBK proofread the final manuscript before submission. All authors read and approved the final manuscript.

\section{Competing interests}

The authors declare that they have no competing interests.

\section{Publisher's Note}

Springer Nature remains neutral with regard to jurisdictional claims in published maps and institutional affiliations.

\section{Author details}

${ }^{1}$ Department of Physiology and Jiangxi Provincial Key Laboratory of Reproductive Physiology and Pathology, Basic Medical College, Nanchang University, Nanchang, Jiangxi 330006, People's Republic of China.

${ }^{2}$ Department of Clinic medicine, School of Queen Mary, Nanchang University, Nanchang, Jiangxi 330006, People's Republic of China. ${ }^{3}$ Department of Physiology, Basic Medical College, Nanchang University, Nanchang, Jiangxi 330006, People's Republic of China.

Received: 14 June 2017 Accepted: 25 August 2017

Published online: 06 September 2017

\section{References}

1. Hanna J, Goldman-Wohl D, Hamani Y, Avraham I, Greenfield C, Natanson-Yaron S, Prus D, Cohen-Daniel L, Arnon TI, Manaster I, et al. Decidual NK cells regulate key developmental processes at the human fetal-maternal interface. Nat Med. 2006;12:1065-74.

2. Bilinski MJ, Thorne JG, Oh MJ, Leonard S, Murrant C, Tayade C, Croy BA. Uterine NK cells in murine pregnancy. Reprod Biomedi Online. $2008 ; 16: 218-26$
3. Paffaro VA, Bizinotto MC, Joazeiro PP, Yamada AT. Subset classification of mouse uterine natural killer cells by DBA lectin reactivity. Placenta. 2003;24: 479-88.

4. King A, Allan DS, Bowen M, Powis SJ, Joseph S, Verma S, Hiby SE, McMichael AJ, Loke YW, Braud VM. HLA-E is expressed on trophoblast and interacts with CD94/NKG2 receptors on decidual NK cells. Eur J Immunol. 2000;30:1623-31.

5. Brusilovsky M, Radinsky O, Yossef R, Campbell KS, Porgador A. Carbohydratemediated modulation of NK cell receptor function: structural and functional influences of heparan sulfate moieties expressed on NK cell surface. Frontiers Oncol. 2014;4:185.

6. Acar N, Ustunel I, Demir R. Uterine natural killer (UNK) cells and their missions during pregnancy: a review. Acta Histochem. 2011;113:82-91.

7. Shemesh A, Tirosh D, Sheiner E, Tirosh NB, Brusilovsky M, Segev R, Rosental B, Porgador A. First trimester pregnancy loss and the expression of alternatively spliced NKp30 Isoforms in maternal blood and placental tissue. Frontiers Immunol. 2015;6:189.

8. Koopman LA, Kopcow HD, Rybalov B, Boyson JE, Orange JS, Schatz F, Masch R, Lockwood CJ, Schachter AD, Park PJ, Strominger JL. Human decidual natural killer cells are a unique NK cell subset with immunomodulatory potential. J Exp Med. 2003;198:1201-12.

9. Dosiou C, Giudice LC. Natural killer cells in pregnancy and recurrent pregnancy loss: endocrine and immunologic perspectives. Endocrine Rev. 2005;26:44-62.

10. Wallace $A E$, Fraser R, Cartwright JE. Extravillous trophoblast and decidual natural killer cells: a remodelling partnership. Hum Reprod Update. 2012;18:458-71.

11. Inoue $T$, Kanzaki $H$, Imai $K$, Narukawa $S$, Katsuragawa $H$, Watanabe $H$, Hirano T, Mori T. Progesterone stimulates the induction of human endometrial CD56+ lymphocytes in an in vitro culture system. J Clin Endocrinol Metab. 1996:81:1502-7.

12. Furukawa S, Hayashi S, Usuda K, Abe M, Ogawa I. The impairment of metrial gland development in tamoxifen exposed rats. Exp Toxicol Pathol : official J Gesellschaft fur Toxikologische Pathologie. 2012;64:121-6.

13. Okada S, Okada H, Sanezumi M, Nakajima T, Yasuda K, Kanzaki H. Expression of interleukin-15 in human endometrium and decidua. Mol Hum Reprod. 2000;6:75-80.

14. Ancelin M, Buteau-Lozano H, Meduri G, Osborne-Pellegrin M, Sordello S, Plout J, Perrot-Applanat M. A dynamic shift of VEGF isoforms with a transient and selective progesterone-induced expression of VEGF189 regulates angiogenesis and vascular permeability in human uterus. Proc National Acad Sci United States of America. 2002;99:6023-8.

15. Chantakru S, Wang W-C, van den Heuvel M, Bashar S, Simpson A, Chen $Q$, Croy BA, Evans SS. Coordinate regulation of lymphocyte-endothelial interactions by pregnancy-associated hormones. J Immunol (Baltimore, Md : 1950). 2003;171:4011-9.

16. Sentman CL, Meadows SK, Wira CR, Eriksson M. Recruitment of uterine NK cells: induction of CXC chemokine ligands 10 and 11 in human endometrium by estradiol and progesterone. J Immunol (Baltimore, Md: 1950). 2004;173:6760-6.

17. Kuang $H$, Peng $H, X u H$, Zhang B, Peng J, Tan Y. Hormonal regulation of uterine natural killer cells in mouse preimplantation uterus. J Mol Histol. 2010;41:1-7.

18. Gibson DA, Greaves E, Critchley HOD, Saunders PTK. Estrogen-dependent regulation of human uterine natural killer cells promotes vascular remodelling via secretion of CCL2. Hum Reprod (Oxford, England). 2015;30:1290-301.

19. Guo W, Li P, Zhao G, Fan H, Hu Y, Hou Y. Glucocorticoid receptor mediates the effect of progesterone on uterine natural killer cells. Am J Reprod Immunol (New York, NY: 1989). 2012;67:463-73.

20. Yao MW, Lim H, Schust DJ, Choe SE, Farago A, Ding Y, Michaud S, Church GM, Maas RL. Gene expression profiling reveals progesterone-mediated cell cycle and immunoregulatory roles of Hoxa-10 in the preimplantation uterus. Mol Endocrinol. 2003;17:610-27.

21. Bogdan A, Berta G, Szekeres-Bartho J. PIBF positive uterine NK cells in the mouse decidua. J Reprod Immunol. 2017;119:38-43.

22. Miyaura $\mathrm{H}$, Iwata M. Direct and indirect inhibition of Th1 development by progesterone and glucocorticoids. J Immunol (Baltimore, Md: 1950). 2002;168:1087-94

23. Henderson TA, Saunders PTK, Moffett-King A, Groome NP, Critchley HOD. Steroid receptor expression in uterine natural killer cells. J Clin Endocrinol I\& Metabolism. 2003;88:440-9. 
24. Borzychowski AM, Chantakru S, Minhas K, Paffaro VA, Yamada AT, He H, Korach KS, Croy BA. Functional analysis of murine uterine natural killer cells genetically devoid of oestrogen receptors. Placenta. 2003;24:403-11.

25. Bombail V, MacPherson S, Critchley HOD, Saunders PTK. Estrogen receptor related beta is expressed in human endometrium throughout the normal menstrual cycle. Hum Reprod. 2008;23:2782-90.

26. Mani $\mathrm{S}$, Mermelstein $\mathrm{P}$, Tetel M, Anesetti $\mathrm{G}$. Convergence of multiple mechanisms of steroid hormone action. Hormone Metabol Res. 2012;44:569-76.

27. Charles NJ, Thomas P, Lange CA. Expression of membrane progesterone receptors (mPR/PAQR) in ovarian cancer cells: implications for progesteroneinduced signaling events. Hormones and Cancer. 2010;1:167-76.

28. Petersen SL, Intlekofer KA, Moura-Conlon PJ. Brewer DNa: nonclassical progesterone Signalling molecules in the nervous system. J Neuroendocrinol. 2013;25:991-1001.

29. Thomas P. Characteristics of membrane progestin receptor alpha (mPRalpha) and progesterone membrane receptor component 1 (PGMRC1) and their roles in mediating rapid progestin actions. Front Neuroendocrinol. 2008;29:292-312.

30. Roberts CW, Walker W, Alexander J. Sex-associated hormones and immunity to protozoan parasites. Clini Microbiol Rev. 2001;14:476-88.

31. Wang F, Zhu H, Li B, Liu M, Liu D, Deng M, Wang Y, Xia X, Jiang Q, Chen D. Effects of human chorionic gonadotropin, estradiol, and progesterone on interleukin-18 expression in human decidual tissues. Gynecol Endocrinol. 2017;33:265-9.

32. Leno-Durn E, Muoz-Fernndez R, Olivares EG, Tirado-Gonzlez I: Liaison between natural killer cells and dendritic cells in human gestation. Cell $1 \&$ Mol Immunol 2014, 11:449-455.

33. Wehner R, Dietze K, Bachmann M, Schmitz M. The bidirectional crosstalk between human Dendritic cells and natural killer cells. J Innate Immunity. 2011:3:258-63.

34. Acevedo HF. Human chorionic gonadotropin ( $\mathrm{hCG}$ ), the hormone of life and death: a review. J Exp therapeutics I\& Oncol. 2002;2:133-45.

35. Keay SD, Vatish M, Karteris E, Hillhouse EW, Randeva HS. The role of hCG in reproductive medicine. BJOG : Int J Obstet Gynaecol. 2004;111:1218-28.

36. Kane N, Kelly R, Saunders PTK, Critchley HOD. Proliferation of uterine natural killer cells is induced by human chorionic gonadotropin and mediated via the mannose receptor. Endocrinology. 2009;150:2882-8.

37. Bischof P, Campana A. Molecular mediators of implantation. Best Practice $1 \&$ Res Clin Obstet I\& Gynaecol. 2000;14:801-14.

38. Sharma S, Godbole G, Modi D. Decidual control of Trophoblast invasion. Am J Reprod Immunol (New York, NY : 1989). 2016;75:341-50.

39. Dimitriadis E, Nie G, Hannan NJ, Paiva P, Salamonsen LA. Local regulation of implantation at the human fetal-maternal interface. The International J Dev Biol. 2010;54:313-22.

40. Mller H, Liu B, Croy BA, Head JR, Hunt JS, Dai G, Soares MJ. Uterine natural killer cells are targets for a trophoblast cell-specific cytokine, prolactin-like protein a. Endocrinology. 1999;140:2711-20.

41. Alam SMK, Konno T, Soares MJ. Identification of target genes for a prolactin family paralog in mouse decidua. Reprod (Cambridge, England). 2015;149:625-32.

42. Ain R, Tash JS, Soares MJ. Prolactin-like protein-a is a functional modulator of natural killer cells at the maternal-fetal interface. Mol Cell Endocrinol. 2003;204:65-74.

43. Robertson MJ. Role of chemokines in the biology of natural killer cells. J Leukoc Biol. 2002:71:173-83.

44. Hanna J, Wald O, Goldman-Wohl D, Prus D, Markel G, Gazit R, Katz G, Haimov-Kochman R, Fujii N, Yagel S, et al. CXCL12 Expression by invasive trophoblasts induces the specific migration of CD16- human natural killer cells. Blood. 2003;102:1569-77.

45. Wu X, Jin LP, Yuan MM, Zhu Y, Wang MY, Li DJ. Human first-trimester trophoblast cells recruit CD56brightCD16- NK cells into decidua by way of expressing and secreting of CXCL12/stromal cell-derived factor 1. J Immunol (Baltimore, Md : 1950). 2005;175:61-8.

46. Wang L, Li X, Zhao Y, Fang C, Lian Y, Gou W, Han T, Zhu X. Insights into the mechanism of CXCL12-mediated signaling in trophoblast functions and placental angiogenesis. Acta Biochim Biophys Sin. 2015;47:663-72.

47. Berahovich RD, Zabel BA, Penfold MET, Lewen S, Wang Y, Miao Z, Gan L, Pereda J, Dias J, Slukvin II, et al. CXCR7 Protein is not expressed on human or mouse leukocytes. J Immunol. 2010;185:5130-9.

48. Piao HL, Wang SC, Tao Y, Fu Q, Du MR, Li DJ. CXCL12/CXCR4 Signal involved in the regulation of trophoblasts on peripheral NK cells leading to Th2 bias at the maternal-fetal interface. Eur Rev Med pharmacol Sci. 2015;19:2153-61.

49. Jones RL, Kelly RW, Critchley HO. Chemokine and cyclooxygenase-2 expression in human endometrium coincides with leukocyte accumulation. Hum Reprod (Oxford, England). 1997;12:1300-6.

50. Arici A, Senturk LM, Seli E, Bahtiyar MO, Kim G. Regulation of monocyte chemotactic protein-1 expression in human endometrial stromal cells by estrogen and progesterone. Biol Reprod. 1999;61:85-90.

51. Pollard JW, Lin EY, Zhu L. Complexity in uterine macrophage responses to cytokines in mice. Biol Reprod. 1998;58:1469-75.

52. Chantakru S, Kuziel WA, Maeda N, Croy BA. A study on the density and distribution of uterine natural killer cells at mid pregnancy in mice genetically-ablated for CCR2, CCR 5 and the CCR5 receptor ligand, MIP-1 alpha. J Reprod Immunol. 2001;49, 33:-47.

53. Nieto M, Navarro F, Perez-Villar JJ, del Pozo MA, Gonzlez-Amaro R, Mellado M, Frade JM, Martnez-A C, Lpez-Botet M, Snchez-Madrid F. Roles of chemokines and receptor polarization in NK-target cell interactions. J Immunol (Baltimore, Md : 1950). 1998;161:3330-9.

54. Elhaik Goldman S, Moshkovits I, Shemesh A, Filiba A, Tsirulsky Y, Vronov E, Shagan M, Apte RN, Benharroch DA, Karo-Atar D, et al. Natural Killer Receptor 1 Dampens the Development of Allergic Eosinophilic Airway Inflammation. PLoS One. 2016;11:e0160779.

55. Borrego F, Kabat J, Kim D-K, Lieto L, Maasho K, Pea J, Solana R, Coligan JE. Structure and function of major histocompatibility complex (MHC) class I specific receptors expressed on human natural killer (NK) cells. Mol Immunol. 2002;38:637-60.

56. Chazara O, Xiong S, Moffett A. Maternal KIR and fetal HLA-C: a fine balance. J Leukoc Biol. 2011;90:703-16.

57. Le Bouteiller P. HLA-G in human early pregnancy: Control of uterine immune cell activation and likely vascular remodeling. Biom J. 2015;38:32-38.

58. Hiby SE, Apps R, Sharkey AM, Farrell LE, Gardner L, Mulder A, Claas FH, Walker JJ, Redman CW, Redman CC, et al. Maternal activating KIRs protect against human reproductive failure mediated by fetal HLA-C2. J Clin Invest. 2010;120:4102-10

59. Hiby SE, Regan L, Lo W, Farrell L, Carrington M, Moffett A. Association of maternal killer-cell immunoglobulin-like receptors and parental HLA-C genotypes with recurrent miscarriage. Hum Reprod (Oxford, England). 2008;23:972-6.

60. Yawata M, Yawata N, Abi-Rached L, Parham P. Variation within the human killer cell immunoglobulin-like receptor (KIR) gene family. Crit Rev Immunol. 2002;22:463-82.

61. Hsu KC, Liu X-R, Selvakumar A, Mickelson E, O'Reilly RJ, Dupont B. Killer Iglike receptor haplotype analysis by gene content: evidence for genomic diversity with a minimum of six basic framework haplotypes, each with multiple subsets. J Immunol (Baltimore, Md : 1950). 2002;169:5118-29.

62. Long W, Shi Z, Fan S, Liu L, Lu Y, Guo X, Rong C, Cui X, Ding H. Association of maternal KIR and fetal HLA-C genes with the risk of preeclampsia in the Chinese Han population. Placenta. 2015;36:433-7.

63. Xiong S, Sharkey AM, Kennedy PR, Gardner L, Farrell LE, Chazara O, Bauer J, Hiby SE, Colucci F, Moffett A. Maternal uterine NK cell-activating receptor KIR2DS1 enhances placentation. J Clin Invest. 2013;123:4264-72.

64. Morin SJ, Treff NR, Tao X, Scott RT, Franasiak JM, Juneau CR, Maguire M, Scott RT. Combination of uterine natural killer cell immunoglobulin receptor haplotype and trophoblastic HLA-C ligand influences the risk of pregnancy loss: a retrospective cohort analysis of direct embryo genotyping data from euploid transfers. Fertil Steril. 2017;107:677-83. e672

65. Szekeres-Bartho J, Par G, Gy D, Smart YC, Volgyi Z. The antiabortive effect of progesterone-induced blocking factor in mice is manifested by modulating NK activity. Cell Immunol. 1997;177:194-9.

66. Anderle C, Hammer A, Polgr B, Hartmann M, Wintersteiger R, Blaschitz A, Dohr G, Desoye G, Szekeres B. Human trophoblast cells express the immunomodulator progesterone-induced blocking factor. J Reprod Immunol. 2008;79:26-36.

67. Yie SM, Xiao R, Librach CL. Progesterone regulates HLA-G gene expression through a novel progesterone response element. Hum Reprod. 2006;21:2538-44.

68. Yie SM, Li LH, Li GM, Xiao R, Librach CL. Progesterone enhances HLA-G gene expression in JEG-3 choriocarcinoma cells and human cytotrophoblasts in vitro. Hum Reprod. 2006;21:46-51.

69. Sheshgiri R, Rao V, Tumiati LC, Xiao R, Prodger JL, Badiwala M, Librach C, Delgado DH. Progesterone induces human leukocyte antigen-g expression in vascular endothelial and smooth muscle cells. Circulation. 2008;118:S58-64. 
70. Blaschitz A, Hutter H, Dohr G. HLA class I protein expression in the human placenta. Early pregnancy. 2001;5:67-9.

71. Blanco O, Tirado I, Muoz-Fernndez R, Abada-Molina AC, Garca-Pacheco JM, Pea J, Olivares EG. Human decidual stromal cells express HLA-G: effects of cytokines and decidualization. Hum Reprod (Oxford, England). 2008;23:144-52.

72. Ulbrecht M, Maier S, Hofmeister V, Falk CS, Brooks AG, McMaster MT, Weiss EH. Truncated HLA-G isoforms are retained in the endoplasmic reticulum and insufficiently provide HLA-E ligands. Hum Immunol. 2004;65:200-8.

73. Clements CS, Kjer-Nielsen L, McCluskey J, Rossjohn J. Structural studies on HLA-G: implications for ligand and receptor binding. Hum Immunol. 2007:68:220-6.

74. Favier B, Lemaoult J, Lesport E, Carosella ED. ILT2/HLA-G interaction impairs NK-cell functions through the inhibition of the late but not the early events of the NK-cell activating synapse. FASEB J. 2010;24:689-99.

75. van der Meer A, Lukassen HGM, van Lierop MJC, Wijnands F, Mosselman S, Braat DDM, Joosten I. Membrane-bound HLA-G activates proliferation and interferon-gamma production by uterine natural killer cells. Mol Hum Reprod. 2004;10:189-95.

76. Cristiani CM, Palella E, Sottile R, Tallerico R, Garofalo C, Carbone E. Human NK cell subsets in pregnancy and disease: toward a new biological complexity. Frontiers Immunol. 2016;7:656.

\section{Submit your next manuscript to BioMed Central} and we will help you at every step:

- We accept pre-submission inquiries

- Our selector tool helps you to find the most relevant journal

- We provide round the clock customer support

- Convenient online submission

- Thorough peer review

- Inclusion in PubMed and all major indexing services

- Maximum visibility for your research

Submit your manuscript at www.biomedcentral.com/submit

) Biomed Central 